NBER WORKING PAPER SERIES

\title{
CATCHING UP WITH THE JONESES: HETEROGENEOUS PREFERENCES AND THE DYNAMICS OF ASSET PRICES
}

\author{
Yeung Lewis Chan \\ Leonid Kogan \\ Working Paper 8607 \\ http://www.nber.org/papers/w8607 \\ NATIONAL BUREAU OF ECONOMIC RESEARCH \\ 1050 Massachusetts Avenue \\ Cambridge, MA 02138 \\ November 2001
}

We thank Andrew Abel, John Campbell, George Chacko, Timothy Chue, Francisco Gomes, John Heaton, Alan Kraus, Chau Minh, Raman Uppal, Luis Viceira, Jiang Wang, the two anonymous referees, and the seminar participants at the City University of Hong Kong, Harvard University, HKUST, the London Business School, MIT PhD seminar, University of British Columbia, University of Texas at Austin, the Wharton School, the European Finance Association 2001 Meetings, the NBER 2001 Summer Institute and the 2000 Western Finance Association conference for valuable comments. John Cochrane provided extensive comments which greatly improved the paper. Financial support from the DAG-HKUST (Chan) and the Rodney L. White Center for Financial Research (Kogan) is gratefully acknowledged. The views expressed herein are those of the authors and not necessarily those of the National Bureau of Economic Research.

(C) 2001 by Yeung Lewis Chan and Leonid Kogan. All rights reserved. Short sections of text, not to exceed two paragraphs, may be quoted without explicit permission provided that full credit, including (C) notice, is given to the source. 
Catching Up with the Joneses:

Heterogeneous Preferences and the Dynamics of Asset Prices

Yeung Lewis Chan and Leonid Kogan

NBER Working Paper No. 8607

November 2001

JEL No. G12, E44

\begin{abstract}
We analyze a general equilibrium exchange economy with a continuum of agents who have "catching up with the Joneses" preferences and differ only with respect to the curvature of their utility functions. While individual risk aversion does not change over time, dynamic redistribution of wealth among the agents leads to countercyclical time variation in the Sharpe ratio of stock returns. We show that both the conditional risk premium and the return volatility are negatively related to the level of stock prices, as observed empirically. Therefore, our model exhibits many of the empirically observed properties of aggregate stock returns, e.g., patterns of autocorrelation in returns, the "leverage effect" in return volatility and long-horizon return predictability. For comparison,otherwise similar representative agent economies with the same type of preferences exhibit counter-factual behavior, e.g., a constant Sharpe ratio of returns and procyclical risk premium and return volatility.
\end{abstract}

Yeung Lewis Chan

Department of Finance

School of Business and Management

Hong Kong University of Science and Technology

Clearwater Bay, Kowloon

Hong Kong

Tel: +852 2358-7683

Email: ylchan@ust.hk
Leonid Kogan

Sloan School of Management

Massachusetts Institute of Technology

50 Memorial Drive, E52-455

Cambridge, MA

and NBER

Tel: 617-253-2289

Email: 1kogan@mit.edu 


\section{Introduction}

Many classical dynamic models such as Lucas (1978) and Cox, Ingersoll and Ross (1985) use the representative investor framework to study determination of asset prices. This approach renders the computation of equilibrium elegantly simple and contributes much to our understanding of how underlying economic structures such as preferences, endowments and production technologies, influence asset prices. As shown in a recent paper by Campbell and Cochrane (1999), many of the empirically observed features of stock prices can be reproduced within a model with a single representative agent whose utility function exhibits countercyclical variation in risk aversion, giving rise to a slowly varying, countercyclical risk premium in stock returns. In this paper we explore a specific economic mechanism leading to countercyclical variation in the conditional risk premium. We study an economy populated by heterogeneous agents whose individual risk aversion is constant over time but varies across the population. The aggregate risk premium in such economy exhibits countercyclical variation due to endogenous changes in the cross-sectional distribution of wealth. Relatively risk tolerant agents hold higher proportion of their wealth in stocks. Therefore, a decline in the stock market reduces the fraction of aggregate wealth controlled by such agents and hence their contribution to the aggregate risk aversion. Thus, the equilibrium risk premium rises as a result of a fall in stock prices.

We calibrate our model to match the basic unconditional moments of stock and bond returns and compare its conditional properties to historical evidence. We find that endogenous changes in conditional moments of returns due to preference heterogeneity are of sufficiently large magnitude to be economically significant. However, changes in expected stock returns in the model are still partly driven by the time varying interest rates, a result of the functional form of individual preferences assumed in our analysis. Thus, while heterogeneous risk preferences can give rise to many of the observed properties of asset returns, the simple structure of our model does not capture all of the important quantitative features of the data.

A representative-agent model can be viewed as a reduced form description of an outcome of the aggregation procedure in an economy populated by heterogeneous agents. Such models are silent about the precise nature of individual investor behavior and hence say nothing about disaggregated variables, such as individual asset holdings and consumption. Our model accounts for investor heterogeneity explicitly. Thus, in addition to relating aggregate consumption to asset prices, it generates implications for individual investor behavior, which can be used to evaluate the empirical plausibility of heterogeneous risk preferences as an explanation of the salient features of the aggregate stock market behavior. In particular, 
we find that individual asset holdings in our model economy are comparable across the population, even though a significant degree of preference heterogeneity is necessary to capture the unconditional properties of asset returns. On the other hand, perfect risk sharing in our model implies sizable cross-sectional differences in individual consumption volatility. This offers a natural target for future extensions of our basic model which is distinct from simply improving its asset pricing implications.

In two related papers, Dumas (1989) and Wang (1996) consider economies in which agents differ in their risk aversion. ${ }^{1}$ Dumas analyzes a two-person production economy with an exogenous stock return process and relies purely on numerical analysis. Wang considers a two-person exchange economy and is able to obtain closed-form expressions for certain bond prices under several specific combinations of individual risk aversion coefficients. Our work differs from theirs in three important aspects. First, while Dumas and Wang emphasize the dynamics and the term structure of interest rates, our main focus is on the behavior of stock prices. Second, they consider time-separable, state-independent utility functions, while preferences in our model exhibit the "catching up with the Joneses" feature. As a result, the asymptotic cross-sectional distribution of wealth is not degenerate in our model, i.e., no single type dominates the economy as aggregate wealth increases without bound, unlike in the exchange economy in Wang (1996). ${ }^{2}$ This result is important since it allows us to discuss the average, long-run properties of asset prices. Finally, unlike their papers, we calibrate our model and assess its quantitative implications relative to historical data.

The rest of the paper is organized as follows. Section 2 describes the model. Section 3 characterizes the competitive equilibrium. Section 4 examines the dynamics of stock returns. Section 5 concludes.

\section{The Model}

We consider a continuous time, infinite horizon exchange economy with complete financial markets and a single perishable consumption good. There is only one source of uncertainty and investors trade in financial securities to share risk.

Our model has two somewhat non-standard elements. First, we assume that agents' preferences exhibit the "catching up with the Joneses" feature of Abel (1990, 1999). Specifically,

\footnotetext{
${ }^{1}$ Other forms of heterogeneity have also been considered in the literature. For instance, Mankiw (1986) and Constantinides and Duffie (1996) argue that differences in investors' non-insurable income process can help explain the equity premium puzzle of Mehra and Prescott (1985). See Brav, Constantinides and Geczy (1999) for some related empirical evidence. In the context of portfolio insurance, Grossman and Zhou (1996) study a finite-horizon exchange economy with two types of agents.

${ }^{2}$ Dumas (1989) demonstrates that the cross-sectional wealth distribution in his model can be stationary under certain assumptions on model parameters. In our model the wealth distribution is always stationary.
} 
we assume that individual utility is a power function of the ratio of individual consumption to the social standard of living. This form of preferences retains the property of the standard CRRA utility function that individual risk aversion does not change over time. Second, we assume that there exists a continuum of investors who differ from each other with respect to the curvature of their utility functions.

The "catching up with the Joneses" feature of preferences guarantees the existence of a non-degenerate stationary cross-sectional distribution of wealth. It also allows the equilibrium interest rate to be relatively low even though the aggregate utility curvature is relatively high. ${ }^{3}$ Time variation in the Sharpe ratio of stock returns comes entirely from preference heterogeneity. Moreover, heterogeneity can give rise to countercyclical variation in return volatility, while we show that in otherwise similar homogeneous economies volatility is procyclical. ${ }^{4}$

\section{Aggregate Endowment}

The aggregate endowment process $Y_{t}$ is described by a geometric Brownian motion

$$
d Y_{t}=\mu Y_{t} d t+\sigma Y_{t} d B_{t}, \quad t \in[0, \infty)
$$

where $B_{t}$ is a standard Brownian motion. Both $\mu$ and $\sigma$ are constants with $\mu>\sigma^{2} / 2$ and $\sigma>0$. Well known properties of this process include its conditional log-normality and non-negativity.

\section{Capital Markets}

There are two long-lived financial securities available for trading: a risky asset, the stock, and a locally riskless instrument. The stock price is denoted by $P_{t}$; the instantaneous risk-free interest rate is denoted by $r_{t}$. There is a single share of the stock outstanding, which entitles its holder to the dividend stream $Y_{t}$. The bond is available in zero net supply.

\section{Preferences and Cross-Sectional Heterogeneity}

In this economy, all investors maximize expected utility of the form

$$
\mathrm{E}_{0}\left[\int_{0}^{\infty} e^{-\rho t} U\left(C_{t}, X_{t} ; \gamma\right) d t\right]
$$

\footnotetext{
${ }^{3}$ In a representative agent model with standard time-separable CRRA utility function, it is difficult to reconcile high values of the Sharpe ratio with low level of the risk-free rate. This "risk-free rate puzzle" is discussed in Weil (1989).

${ }^{4}$ The procyclical behavior of volatility in this context means that a high level of the price-dividend ratio or a large increase in stock prices is associated with higher levels of volatility. Alternatively, changes in volatility are positively correlated with stock returns.
} 
where

$$
U\left(C_{t}, X_{t} ; \gamma\right)=\frac{1}{1-\gamma}\left(\frac{C_{t}}{X_{t}}\right)^{1-\gamma}
$$

$C_{t}$ is the consumption rate at time $t . X_{t}$ is a state variable treated as exogenous by individual investors, which will be given an interpretation of the standard of living in the economy. The time-discount rate $\rho$ is common to all investors. The only agent-specific feature of preferences is the curvature parameter $\gamma$, which measures individual risk aversion with respect to consumption gambles. $\gamma$ can be equivalently interpreted as the individual risk aversion coefficient with respect to wealth gambles, just as with standard CRRA utility function. Because the utility function is homothetic in consumption and individuals treat the process $X_{t}$ as exogenous, the indirect utility function over wealth is also homothetic, of the form $1 /(1-\gamma) W_{t}^{1-\gamma} h\left(X_{t}, \cdot\right)$, where the multiplier $h\left(X_{t}, \cdot\right)$ depends also on the current investment opportunity set. The only distinction from the standard CRRA case is the dependence of $h$ on $X_{t}$. Thus, the relative risk aversion coefficient with respect to wealth gambles is also equal to $\gamma$ and does not change over time. While such a dual interpretation of $\gamma$ is possible at an individual level, it does not hold in the aggregate, since the utility function of the representative agent is derived from individual preferences and is not homothetic in general (unless all agents in the economy have identical preferences). Thus, the "ratio" functional form of preferences in (2) is particularly convenient for isolating the effects of preference heterogeneity. Any kind of time-variation in the aggregate risk aversion must be due to the differences in $\gamma$ across investors.

The specification in (2) implies that the utility of the investor is influenced not only directly by her own consumption, but also by the standard of living of others. Abel (1990, 1999) refers to preferences of this type as "catching up with the Joneses" - a higher standard of living $X_{t}$ provides a complementary effect on current consumption. ${ }^{5}$ Formally, complementarity of the standard of living and individual consumption requires that

$$
\frac{\partial U_{C}\left(C_{t}, X_{t} ; \gamma\right)}{\partial X_{t}}=(\gamma-1) C_{t}^{-\gamma} X_{t}^{\gamma-2} \geq 0
$$

Thus, we restrict our analysis to $\gamma \geq 1$. We allow for a continuum or a finite collection of preference types, defined over $\gamma \in[1, \infty)$.

\footnotetext{
${ }^{5}$ This type of preferences is often referred to as "external habit formation". Various specifications of representative agent models with habit formation have been analyzed in the literature. Major contributions in continuous time setting include Ryder and Heal (1973), Sundaresan (1989), Constantinides (1990), Detemple and Zapatero (1991), Hindy and Huang (1992, 1993), Hindy, Huang and Zhu (1997). Abel (1990, 1999), Gali (1994), and Campbell and Cochrane (1999) consider discrete-time models. Bakshi and Chen (1996) develop a related model in which agents derive utility directly from their social status, measured by their wealth relative to the social wealth index. On the empirical side, Campbell and Cochrane (1999), Ferson and Constantinides (1991), and Heaton (1995) confront such models with historical data and find that they overcome many of the shortcomings of standard models with time-separable, state-independent preferences.
} 
Our specification of preferences differs from Abel's in the definition of the process $X_{t}$. We define $X_{t}$ as a weighted geometric average of past realizations of the aggregate endowment process $^{6}$

$$
x_{t}=x_{0} e^{-\lambda t}+\lambda \int_{0}^{t} e^{-\lambda(t-s)} y_{s} d s,
$$

where $x_{t}=\ln \left(X_{t}\right)$ and $y_{t} \equiv \ln \left(Y_{t}\right)$. Abel allows $X_{t}$ to depend on the agent's own consumption as well. More importantly, he restricts the history dependence in $X_{t}$ to a single lag in a discrete-time model. Our use of an infinite moving average in (4) reduces variability of the expected growth rate of the marginal utility of consumption, lowering the volatility and increasing the persistence of the interest rate in equilibrium.

Definition (4) justifies the interpretation of $X_{t}$ as the standard of living. One can see that the parameter $\lambda$ governs the degree of history-dependence in $X_{t}$. When $\lambda \gg \sigma^{2}, x_{t} \approx y_{t}$, i.e., the standard of living tracks closely the most recent realizations of the aggregate endowment. On the other hand, if $\lambda \approx 0$, then $X_{t}$ is influenced heavily by the past history.

It is convenient to describe the state of the economy in terms of the variable $\omega_{t} \equiv y_{t}-x_{t}$. Since $\omega_{t}$ measures aggregate consumption relative to the standard of living, $\omega_{t}=\ln \left(Y_{t} / X_{t}\right)$, we call it relative (log) consumption. Naturally, a high (low) relative consumption value is interpreted as a good (bad) state of the economy. Given the lognormal specification of the aggregate endowment process, relative consumption is conditionally normally distributed and follows a linear mean-reverting process

$$
d \omega_{t}=-\lambda\left(\omega_{t}-\bar{\omega}\right) d t+\sigma d B_{t}
$$

with the long-run mean and standard deviation given by

$$
\begin{aligned}
\bar{\omega} & \equiv \lim _{t \rightarrow \infty} \mathrm{E}_{0}\left(\omega_{t} \mid \omega_{0}\right)=\frac{\mu-\sigma^{2} / 2}{\lambda} \\
\sigma[\omega] & \equiv\left(\lim _{t \rightarrow \infty} \operatorname{Var}_{0}\left(\omega_{t} \mid \omega_{0}\right)\right)^{1 / 2}=\frac{\sigma}{\sqrt{2 \lambda}} .
\end{aligned}
$$

The behavior of relative consumption reflects the slow-moving nature of the standard of living process. Aggregate endowment shocks get incorporated into the relative consumption variable instantaneously and then decay exponentially at rate $\lambda$, as the standard of

\footnotetext{
${ }^{6}$ In equilibrium of our exchange economy model there is no distinction between the aggregate endowment and the aggregate consumption, as a result of market clearing in the goods markets. Hence, one can equivalently think of $X_{t}$ as a weighted average of past realizations of the aggregate consumption. In other contexts, however, the two definitions are not equivalent. It may be convenient to define the standard of living in terms of income of other agents in the economy, as opposed to their consumption, as such definition circumvents the externality problems that otherwise drive a wedge between the competitive equilibrium and the solution of the central planner's problem. However, formal analysis of these two alternative modeling approaches is beyond the scope of this paper.
} 
living process slowly adapts to the new level of endowment. Higher values of $\lambda$ imply lower persistence and lower steady-state variance of relative consumption.

\section{The Competitive Equilibrium}

In this section we analyze the general properties of the competitive equilibrium in the heterogeneous-agent economy. We solve the model in three steps, as is standard in the literature (e.g., Karatzas et al. (1990), Wang (1996)). First, we analyze the social planner's problem in order to obtain the optimal consumption sharing rule. Then, we construct an Arrow-Debreu economy to support the optimal allocation found in the planner's problem. Finally, we implement the Arrow-Debreu equilibrium as a sequential-trade economy.

\section{The Social Planner's Problem}

The social planner distributes the aggregate endowment among the consumers so that the resulting allocation is Pareto optimal. We assume without loss of generality that there is only one investor of each type and $f(\gamma)$ is the social weight attached by the planner to type $\gamma^{7}$ Given the distribution of social weights $f(\gamma)$, the objective of the social planner is

$$
\sup _{\left\{C_{t}\left(Y_{t}, X_{t} ; \gamma\right)\right\}} \mathrm{E}_{0}\left[\int_{0}^{\infty} e^{-\rho t}\left[\int_{1}^{\infty} f(\gamma) \frac{1}{1-\gamma}\left(\frac{C_{t}\left(Y_{t}, X_{t} ; \gamma\right)}{X_{t}}\right)^{1-\gamma} d \gamma\right]\right] d t
$$

subject to the resource constraint,

$$
\int_{1}^{\infty} \frac{C_{t}\left(Y_{t}, X_{t} ; \gamma\right)}{X_{t}} d \gamma \leq \frac{Y_{t}}{X_{t}}, \quad \forall t \in[0, \infty)
$$

Since there is no intertemporal transfer of resources, this optimization reduces to a static problem. At each point in time and in each state of the economy, the planner solves

$$
\sup _{\left\{C_{t}\left(Y_{t}, X_{t} ; \gamma\right)\right\}} \int_{1}^{\infty} f(\gamma) \frac{1}{1-\gamma}\left(\frac{C_{t}\left(Y_{t}, X_{t} ; \gamma\right)}{X_{t}}\right)^{1-\gamma} d \gamma
$$

subject to the resource constraint (6). The following lemma summarizes the optimal sharing rule.

Lemma 1 The optimal consumption sharing rule is given by

$$
\begin{aligned}
C_{t}^{*}\left(Y_{t}, X_{t} ; \gamma\right) & =c_{t}^{*}\left(\omega_{t} ; \gamma\right) Y_{t}, \\
c_{t}^{*}\left(\omega_{t} ; \gamma\right) & =f(\gamma)^{\frac{1}{\gamma}} e^{-\frac{1}{\gamma} z\left(\omega_{t}\right)-\omega_{t}} .
\end{aligned}
$$

\footnotetext{
${ }^{7}$ For technical reasons, it is convenient to assume that the distribution $f(\gamma)$ has a compact support.
} 
$z\left(\omega_{t}\right)$ is the logarithm of the shadow price of the resource constraint (6), and is characterized by

$$
\int_{1}^{\infty} f(\gamma)^{\frac{1}{\gamma}} e^{-\frac{1}{\gamma} z\left(\omega_{t}\right)-\omega_{t}} d \gamma=1
$$

Lemma 1 shows that individual consumption, as a fraction of the aggregate endowment, is a function of relative consumption $\omega_{t}$, which is a stationary state variable. Thus, consumption (and hence wealth) of all investors grows at the same average rate and no single agent dominates the economy in the long run. In contrast, a heterogeneous economy in which agents have standard time-separable CRRA preferences with the same time discount rate is eventually dominated by the least risk averse agent, as shown in Wang (1996). This difference between the two models is due to the "catching up with the Joneses" feature of preferences. In Wang's exchange economy, at high levels of consumption, the marginal utility of investors with low values of $\gamma$ is relatively high. Thus, they are allocated a larger fraction of the aggregate endowment. This is not the case in our economy, because high levels of consumption are associated with high levels of the social standard of living $X_{t}$, which has a larger impact on the marginal utility of investors with high values of $\gamma$. Therefore, the "catching up with the Joneses" feature has an equalizing effect on marginal utilities of agents with different curvature parameters. As a result, the shares of the aggregate endowment allocated to individual agents remain stationary over time and depend on the ratio of the aggregate endowment to the standard of living.

\section{The Arrow-Debreu Economy}

It is well known that the Pareto optimal allocation (7-9) can be supported as an equilibrium allocation in a particular Arrow-Debreu economy (e.g., Duffie and Huang (1985)). In this economy, agents can trade in primitive state-contingent claims, which pay off a unit of consumption in a particular state of the economy and zero otherwise. Let $\xi_{t, s}$ denote the stochastic discount factor in such economy, then the price of an arbitrary payoff stream $\left\{F_{s}, s \in[t, \infty)\right\}$ at time $t$ is given by $\mathrm{E}_{t}\left[\int_{t}^{\infty} \xi_{t, s} F_{s} d s\right] . \xi_{t, s}$ can be expressed in terms of the shadow price of the resource constraint in the social planner's problem,

$$
\xi_{t, s}=\exp \left(-\rho(s-t)-z_{t}+z_{s}+x_{t}-x_{s}\right), \quad t \leq s .
$$

\section{The Sequential-Trade Economy}

Given the Arrow-Debreu equilibrium, a sequential-trade equilibrium can be constructed, in which investors trade continuously in a small number of long-lived securities. Duffie and Huang (1985) provide general analysis of such an implementation problem. Their results 
can be extended to our setting using arguments similar to those in Wang (1996, Lemma 3). ${ }^{8}$

Prices of long-lived assets in equilibrium are determined by the prices of primitive ArrowDebreu claims. In particular, the stock price satisfies

$$
P_{t}=\mathrm{E}_{t}\left[\int_{t}^{\infty} \xi_{t, s} Y_{s} d s\right]=\mathrm{E}_{t}\left[\int_{t}^{\infty} e^{-\rho(s-t)-z_{t}+z_{s}+x_{t}-x_{s}} Y_{s} d s\right],
$$

while the instantaneous interest rate is given by

$$
r_{t}=\lim _{\Delta t \searrow 0} \frac{\mathrm{E}_{t}\left[\xi_{t, t+\Delta t}-1\right]}{\Delta t}=\lim _{\Delta t \searrow 0} \frac{\mathrm{E}_{t}\left[e^{-\rho \Delta t-z_{t}+z_{t+\Delta t}+x_{t}-x_{t+\Delta t}}-1\right]}{\Delta t} .
$$

\section{Asset Prices}

In this section we analyze the dynamics of asset prices. We point out qualitative and quantitative differences in the behavior of stock returns in heterogeneous and homogeneous economies and argue that these differences can be understood in terms of the evolution of the cross-sectional distribution of wealth over time.

\subsection{Theoretical Characterization}

While the general expression for the stock price is provided by (11), a more explicit characterization would facilitate further qualitative analysis. The following lemma provides a characterization of the stock price.

Lemma 2 The equilibrium price-dividend ratio is given by

$$
\frac{P_{t}}{Y_{t}}=p\left(\omega_{t}\right) \equiv e^{-z\left(\omega_{t}\right)-\omega_{t}} E_{t}\left[\int_{t}^{\infty} e^{-\rho(s-t)+z\left(\omega_{s}\right)+\omega_{s}} d s \mid \omega_{t}\right] .
$$

The expression (13) shows that the price-dividend ratio $P_{t} / Y_{t}$ depends only on relative consumption $\omega_{t}$. The price-dividend ratio summarizes the conditional expectations of future discount rates and dividend growth rates. Under our specification of the aggregate endowment process, future dividend growth is independent of the current state of the economy.

\footnotetext{
8 To use the results in Duffie and Huang (1985), one needs to establish that the financial markets are dynamically complete. In our economy there is only one source of uncertainty, hence to ensure dynamic completeness the volatility of stock returns must be positive almost surely. For economies populated with identical agents with $\gamma \geq 1$ this follows from the fact that the price-dividend ratio is nondecreasing in relative consumption, which implies that $\sigma_{R, t} \geq \sigma$ (see the Appendix). A general result for heterogeneous economies is difficult to establish, although our numerical simulations confirm that the volatility of returns is strictly positive. However, dynamic completeness is easy to guarantee by introducing continuously re-settled financial contracts with unit volatility and endogenously determined rate of return. See Karatzas et al. (1990) for a formal construction.
} 
Thus, the price-dividend ratio depends only on the distribution of future discount rates. The higher the future discount rates, the lower the price-dividend ratio.

To relate (13) to standard results, consider as an example a representative agent economy with logarithmic preferences. When there is only one type with $\gamma=1$, (9) becomes $\exp \left(-z\left(\omega_{t}\right)-\omega_{t}\right)=1$ and therefore $z\left(\omega_{t}\right)=-\omega_{t}$. As a result, the price-dividend ratio is constant:

$$
\frac{P_{t}}{Y_{t}}=\mathrm{E}_{t}\left[\int_{t}^{\infty} e^{-\rho(s-t)} d s\right]=\frac{1}{\rho},
$$

which is the well-known solution.

In our complete-market economy, the stochastic discount factor $\xi_{t, s}$ in (10) is uniquely determined in equilibrium and can be used to analyze the conditional moments of asset returns (see, e.g., Duffie (1996, Section 6.D)). The key property of our model is the countercyclical behavior of the Sharpe ratio of stock returns in equilibrium. This property is important, since it leads to empirically plausible patterns of predictability in stock returns, as documented below. Preference heterogeneity provides an intuitive economic mechanism for generating such countercyclical behavior of the Sharpe ratio. ${ }^{9}$

Lemma 3 If the economy is populated by more than a single type of agents, the instantaneous Sharpe ratio of stock returns is a monotonically decreasing function of relative consumption. It is given by

$$
\frac{\mu_{R, t}-r_{t}}{\sigma_{R, t}}=-\sigma z^{\prime}\left(\omega_{t}\right)
$$

where $z\left(\omega_{t}\right)$ is the logarithm of the shadow price of the resource constraint characterized by (9) and $\mu_{R, t}$ and $\sigma_{R, t}$ denote the instantaneous mean and volatility of stock returns.

The result of Lemma 3 can be seen as an outcome of the endogenous re-distribution of wealth in the economy. Agents with relatively low risk aversion coefficients hold higher proportion of their wealth in stocks. Therefore, a decline in the stock market reduces the fraction of aggregate wealth controlled by such agents. To induce the agents to hold the entire stock market in the aggregate, the equilibrium compensation for risk (the Sharpe ratio) must rise.

The following lemma provides expressions for the risk-free rate and the mean and volatility of stock returns.

\footnotetext{
${ }^{9}$ The Sharpe ratio of stock returns in our model is proportional to the curvature of the utility function of the representative agent. In the context of a one-period Arrow-Debreu economy populated by CRRA-utility agents who differ in their risk aversion, Benninga and Mayshar (1997) show that such curvature is decreasing in the level of the aggregate endowment. Lemma 3 is mathematically equivalent to their result.
} 
Lemma 4 The instantaneous interest rate $r_{t}$ is given by

$$
r_{t}=\rho+\lambda\left(\omega_{t}-\bar{\omega}\right) z^{\prime}\left(\omega_{t}\right)+\lambda \omega_{t}-\frac{1}{2} \sigma^{2} z^{\prime \prime}\left(\omega_{t}\right)
$$

The conditional moments of stock returns are given by

$$
\begin{aligned}
\sigma_{R, t} & =\sigma\left(1+\frac{p^{\prime}\left(\omega_{t}\right)}{p\left(\omega_{t}\right)}\right), \\
\mu_{R, t} & =r_{t}-\sigma z^{\prime}\left(\omega_{t}\right) \sigma_{R, t} .
\end{aligned}
$$

\subsection{Simulation Results}

In this section we quantify the effects of preference heterogeneity. We calibrate our model using several unconditional moments of historical asset returns and then investigate the dynamics of conditional moments. We also highlight the impact of heterogeneity by comparing heterogeneous and homogeneous economies.

\section{Calibration}

In choosing model parameters we use historical returns of S\&P 500 index, commercial paper returns, and per capita consumption over the 1889-1994 period. All returns and consumption data are real. We focus on the century-long sample, as opposed to the post-war sample. We do this for two reasons. First, the post-war sample presents a much tougher target for calibration, because of the relatively low volatility of consumption and the risk-free rate and the relatively high Sharpe ratio of stock returns. As a result, our choice of individual preferences and the cross-sectional distribution of agent types assumed below do not allow us to match the unconditional moments of the data with high accuracy. This makes it difficult to interpret the implications of the model for the conditional properties of returns. Second, historical periods like Great Depression cannot be ruled out ex ante, therefore omitting them from the sample might misrepresent the average properties of asset returns. Thus, we opt for using the century-long sample in our calibration, acknowledging that the basic form of our model has difficulty in matching the moments of the post-war sample period.

We choose the mean and standard deviation of the endowment process, $\mu$ and $\sigma$, to match the corresponding values of per capita aggregate consumption. As in the data, we average the consumption level over every year. We assume that the cross-sectional distribution of weights in the objective of the social planner is described by

$$
f(\gamma)=(\gamma-1) \exp \left(-a_{1} \gamma-a_{2} \gamma^{2}\right)
$$

We choose parameters $a_{1}$ and $a_{2}$ together with the time discount rate $\rho$ and the persistence 
parameter $\lambda$ to match closely the first two moments of excess returns on stocks and the risk-free rate. Table 1 summarizes our parameter choices. A summary of the implied unconditional moments of the model is presented in Table 2. ${ }^{10}$ By construction, the model reproduces the first two moments of stock and bond returns. It also gives rise to a highly persistent risk-free rate. This is due to the fact that the state variable, relative consumption, is slow-moving. This is an improvement over the one-lag discrete time model of Abel (1990), in which the risk-free rate is highly volatile and has low persistence. The average price-dividend ratio in the model is comparable to that in historical data, but the long-run standard deviation of the ratio is higher than empirically observed.

For comparison, we also calibrate a model with a single type of agents. The homogeneous model is not capable of simultaneously reproducing the same four unconditional moments of returns. Therefore, we set the parameters with an objective of minimizing the volatility of the risk-free rate, while matching closely the remaining three of the four moments. Parameter values and the key properties of the homogeneous model are summarized in Tables 1, 2. Overall, the performance of the homogeneous model is comparable to that of the heterogeneous model in terms of replicating the unconditional moments of stock and bond returns, except that the interest rate volatility is relatively high.

\section{Conditional Moments of Returns}

The key to understanding the properties of stock returns in the model is through the relations between conditional moments of returns and relative consumption. Figure 2 shows that the price-dividend ratio is a monotonically increasing function of relative consumption. This is intuitive given the countercyclical behavior of expected stock returns, as shown below. Thus, conditional moments of returns can be equivalently stated in terms of the level of stock prices.

The main effect of preference heterogeneity can be seen in the behavior of the Sharpe ratio of returns. As we have established in Lemma 3, the Sharpe ratio in a heterogeneous economy is countercyclical, while it is constant in economies populated by a single type of agents. ${ }^{11}$ The negative relation between the Sharpe ratio and relative consumption is

\footnotetext{
10 The real risk-free rate is not directly observable and only ex-post real returns can be constructed from the data. The standard deviation of ex-post returns on commercial paper overstates the actual volatility of the risk free rate due to unanticipated inflation. For the same reason, realized real returns on bonds are less persistent than the expected real rate of return. Campbell, Lo and MacKinlay (1997, p.329) argue that historical volatility of the ex-ante real rate of return on short-term bonds is close to $3 \%$, which is consistent with the results in Siegel (1992). This is the number we use in our calibration. We estimate the historical autocorrelation coefficient based on both nominal returns on commercial paper and the ex-post real returns. Ex-post returns are less persistent than nominal returns.

${ }^{11}$ Ferson and Harvey (1991) and Harvey (1991) provide empirical evidence on countercyclical variation in
} 
shown in Panel A of Figure 3. The Sharpe ratio varies significantly over time. The long-run standard deviation of the Sharpe ratio in the heterogeneous model is 0.06 and its long-run mean is 0.32. As we have argued above, the countercyclical behavior of the Sharpe ratio is driven by the endogenous re-distribution of wealth in the economy. Figure 4 illustrates the cross-sectional distribution of wealth implied by our choice of model parameters and the utility weights in (18). We plot the wealth distribution for three different values of relative consumption: $\bar{\omega}-\sigma[\omega], \bar{\omega}$, and $\bar{\omega}+\sigma[\omega]$, representing a below-average, the average, and an above-average states of the economy. In each case the distribution has a similar shape. A decline in relative consumption shifts the mass of the wealth distribution towards the types with higher risk aversion, increasing the Sharpe ratio.

Panel B of Figure 3 presents the conditional volatility of returns as a function of relative consumption. Again, the effect of preference heterogeneity is clear. While the conditional volatility in any homogeneous economy is procyclical (this general result is established in the Appendix), a heterogeneous economy can exhibit a countercyclical pattern in volatility. This effect requires a sufficient degree of preference heterogeneity and depends on the shape of the cross-sectional wealth distribution. ${ }^{12}$ Intuition for why preference heterogeneity can change the pattern of conditional volatility is suggested by the following observation. While the conditional volatility increases with relative consumption in homogeneous economies, it also appears to rise with the risk aversion parameter across the homogeneous economies. We illustrate this in Figure 5 by plotting the conditional volatility of returns in homogeneous economies with different values of the risk aversion parameter, holding other parameters fixed at their calibrated values shown in Table 1. A fall in relative consumption leads to two effects. If the aggregate risk aversion remained constant, the direct effect would be a decline in conditional volatility. However, since the wealth distribution shifts towards more risk averse agents, the indirect effect is an increase in conditional volatility. The second effect dominates when the degree of cross-sectional heterogeneity is sufficiently high. Thus, the countercyclical variation in conditional volatility in the heterogeneous economy can be informally attributed to an effective shift across homogeneous economies with different levels of aggregate risk aversion.

the market price of risk and expected returns. These moments are negatively related to the price-dividend ratio and are higher during business cycle troughs than during peaks.

12 If one assumes that most of the agents in the economy have risk aversion coefficients close to one, it is possible to show using asymptotic analysis that the countercyclical pattern in conditional volatility arises if the cross-sectional dispersion of risk aversion coefficients is sufficiently high relative to the "average" risk aversion. See Chan and Kogan (2000) for formal derivations. 


\section{Predictability of Stock Returns}

To analyze the patterns of predictability in stock returns, we simulate 50, 000 years of returns and compute the population values of several commonly used statistics. In our analysis we focus on excess stock returns to isolate the effect of the time-varying expected return from the impact of the time-varying interest rate. We compare the properties of the model with the corresponding empirical estimates. To emphasize the effect of preference heterogeneity, we also present the statistics for the homogeneous model calibrated to the same set of unconditional moments of returns as the heterogeneous model.

The first two panels of Table 3 show that excess stock returns in the heterogeneous model exhibit univariate mean reversion. In the second panel, individual autocorrelations are aggregated into partial sums to cope with the fact that individual coefficients are poorly measured. The resulting coefficients are negative in sign, as in historical data. This negative autocorrelation in the model is due to the countercyclical behavior of the Sharpe ratio and conditional volatility of excess returns, which implies that a decline in stock prices leads to an increase in expected excess returns. In contrast, the homogeneous model produces slightly positive autocorrelation coefficients. This is because the Sharpe ratio of stock returns is constant in the homogeneous model and conditional volatility is procyclical, therefore expected excess returns are procyclical as well.

The price-dividend ratio forecasts excess stock returns with a negative sign in the heterogeneous model, as shown in the third panel of Table 3 and in Table 4. While the sign of this relation is consistent with empirical observations, the explanatory power of the pricedividend ratio in long-horizon predictive regressions is smaller than in the data. However, if we were to estimate the same relations for stock returns, as opposed to returns in excess of the risk-free rate, the slopes and the $R^{2}$ s would increase approximately by a factor of 4 and 10 respectively, matching closely the corresponding empirical numbers. This suggests that the reason for the relatively small magnitude of the effects in Table 4 is that stock returns are

partly predictable due to the changes in the risk-free rate. One can further see this through a decomposition of the instantaneous expected stock return as a sum of the risk-free rate and the risk premium (expected excess return). Figure 6 shows that the countercyclical nature of expected returns in our heterogeneous model is partly due to the varying risk premium and partly to the varying interest rate. This is an advance over the homogeneous model, in which the conditional risk premium is procyclical and therefore the negative relation between the price-dividend ratio and returns is driven entirely by the dynamics of interest rates. Thus, it is preference heterogeneity that generates negative variation in the risk premium. However, a significant fraction of stock return predictability in the heterogeneous model is still due to 
time variation in the risk-free rate, which is a feature of our preference specification (2). In particular, the long-run standard deviation of the risk-free rate is $2.9 \%$, compared to $1.7 \%$ for the risk premium. This explains the magnitude of the $R^{2} \mathrm{~s}$ in the predictive regressions in Table 4. Subtracting the risk-free rate from stock returns significantly reduces the variance of the remaining predictable component of returns.

The last panel of Table 3 shows that the price-dividend ratio forecasts volatility of returns for many years ahead. In particular, a decline in stock prices predicts an increase in volatility. This is intuitive in light of the behavior of the instantaneous conditional volatility of returns (see Figure 3, Panel B). This pattern of cross-correlations between the price-dividend ratio and the absolute value of returns is similar to the one observed empirically and is consistent with the well-known "leverage effect" (e.g., Black (1976), Schwert (1989), Campbell and Hentschel (1992)). For comparison, the homogeneous model generates a counter-factual positive relation between the level of prices and future volatility of returns, demonstrating that the negative relation must be due to preference heterogeneity.

\section{Wealth Distribution and Individual Policies}

In addition to evaluating the implications of our model for asset prices, one can judge the plausibility of its economic mechanism based on the properties of individual investor behavior required to produce sizable variation in conditional moments of stock returns. In particular, since time-variation in the aggregate risk premium in our model is driven entirely by heterogeneity in individual risk exposure and resulting changes in the cross-sectional wealth distribution, we quantify the cross-sectional distribution of asset holdings within the model. To further assess the effect of risk sharing among heterogeneous agents, we also document the properties of individual consumption processes.

Individual portfolios policies can be conveniently summarized by individual exposure to the aggregate market risk. As one would expect, less risk averse agents invest a higher fraction of their wealth in risky assets. We document the cross-sectional dispersion in individual risk exposure in Figure 7. Specifically, we compute the instantaneous betas of individual wealth processes with respect to the aggregate stock market and plot the cross-sectional distribution of such betas. While Figure 4 shows that individual risk aversion coefficients vary widely across the population, according to Figure 7 most of the time more than ninety percent of total wealth is controlled by individuals with risk exposure between .88 and 1.2. Thus, the magnitude of the cross-sectional dispersion in individual risk exposure within the model does not seem excessive and leverage ratios for most individuals are relatively low. The intuition behind this finding can be understood by considering the equilibrium consumption policies of individuals with high values of $\gamma$. In the limit of risk aversion approaching infinity, Lemma 
1 shows that the consumption policy of such agents is proportional to the standard of living process, scaled appropriately to satisfy the individual budget constraint. Due to the catching up with the Joneses feature of preferences, high- $\gamma$ agents are reluctant to substitute their relative consumption over time, therefore their consumption tracks closely the economy-wide standard of living. Thus, the wealth process of a high- $\gamma$ agent is approximately proportional to the present discounted value of a financial asset with cash flows equal to the standard of living $X_{t}$. The process $X_{t}$ is in turn a moving average of the aggregate endowment and has similar long-run behavior. Hence, the wealth process of high- $\gamma$ individuals is close to the (scaled) value of the claim on aggregate endowment and its market beta is close to one. According to Figure 4, a significant fraction of the total wealth in the economy is controlled by agents with relatively high risk aversion, explaining the concentration of individual risk exposure around one in Figure 4.

The above argument also explains why the consumption of high- $\gamma$ agents has relatively low instantaneous volatility. This is because it closely tracks the process for the standard of living $X_{t}$, which is locally deterministic. Market clearing implies that the agents with low values of the curvature parameter must absorb a larger portion of the aggregate endowment volatility. To quantify the implications of risk sharing in our model economy for individual consumption processes, we plot the cross-sectional distribution of instantaneous consumption volatility in Figure 8. Approximately seventy five percent of the aggregate wealth is controlled by agents with consumption volatility below the volatility of the aggregate endowment. However, ten percent of the aggregate wealth belongs to agents with consumption volatility at least two and a half times higher than that of the aggregate. Although empirically the time-series properties of individual consumption are difficult to measure precisely, the fact that our model implies a substantial degree of dispersion in volatility of individual consumption across the population could be viewed as one of its limitations. The basic model of this paper could be extended in a number of directions with the objective of improving its cross-sectional implications. Heterogeneity in individual risk exposure could arise not only due to differences in risk aversion, but also from differences in beliefs, access to capital markets, idiosyncratic uninsurable risk, etc. ${ }^{13}$ Incorporating these additional dimensions of heterogeneity could help produce realistic cross-sectional features of individual policies. Generalizing the framework of this paper while retaining its tractability poses a challenge for future research.

\footnotetext{
${ }^{13}$ Several papers make progress along these dimensions, e.g., Detemple and Murthy (1994), Constantinides and Duffie (1996), Basak and Cuoco (1998), Heaton and Lucas (1996, 1999), Storesletten et al. (2001).
} 


\section{Conclusion}

Representative agent models identify economic mechanisms that generate empirically observed features of asset prices. One such mechanism is countercyclical variation in the aggregate risk aversion and the market price of risk, as shown by Campbell and Cochrane (1999). This effect arises in our model as a result of heterogeneity in risk preferences among the agents. In a heterogeneous economy, moves in the stock market trigger changes in the cross-sectional distribution of wealth, which we show to cause countercyclical variation in the conditional risk premium and volatility of stock returns.

While endogenous changes in aggregate risk aversion contribute with the right sign to the pattern of time variation in expected returns and volatility, a nontrivial fraction of expected return variation in our model is still due to changes in the risk-free rate. This property of the model is explained by our choice of the specific functional form of preferences. Thus, we cannot argue that the observed empirical properties of stock returns should be attributed to heterogeneous risk preferences alone. Nevertheless, the ability of our heterogeneous-agent model to replicate various qualitative features of aggregate stock returns is encouraging. It suggests that many salient features of the data can arise naturally as a result of interaction of rational investors with different risk preferences. 


\section{Appendix}

\section{Proof of Lemma 1}

Let

$$
c_{t}\left(Y_{t}, X_{t} ; \gamma\right) \equiv \frac{C_{t}\left(Y_{t}, X_{t} ; \gamma\right)}{Y_{t}}
$$

The sharing rule in (7) and (8) is simply the first order condition for consumption in the social planner's static optimization problem:

$$
\begin{aligned}
& \sup _{c_{t}\left(Y_{t}, X_{t} ; \gamma\right)} \int_{1}^{\infty} f(b) \frac{1}{1-\gamma}\left(c_{t}\left(Y_{t}, X_{t} ; \gamma\right) \frac{Y_{t}}{X_{t}}\right)^{1-\gamma} d \gamma, \quad \text { s.t. } \quad \int_{1}^{\infty} c_{t}\left(Y_{t}, X_{t} ; \gamma\right) \frac{Y_{t}}{X_{t}} d \gamma=\frac{Y_{t}}{X_{t}} \\
\Longleftrightarrow & \inf _{Z_{t} \geq 0} \sup _{c_{t}\left(Y_{t}, X_{t} ; \gamma\right)} \int_{1}^{\infty} f(\gamma) \frac{1}{1-\gamma}\left(c_{t}\left(Y_{t}, X_{t} ; \gamma\right)\right)^{1-\gamma} e^{(1-\gamma) \omega_{t}} d \gamma-Z_{t} \cdot \frac{Y_{t}}{X_{t}} \cdot\left(\int_{1}^{\infty} c_{t}\left(Y_{t}, X_{t} ; \gamma\right) d \gamma-1\right)
\end{aligned}
$$

where $Z_{t}$ is the Lagrange multiplier (shadow price) of the constraint. Thus,

$$
\begin{aligned}
c_{t}^{*}\left(Y_{t}, X_{t} ; \gamma\right) & =f(\gamma)^{\frac{1}{\gamma}} e^{-\frac{1}{\gamma} z_{t}-\omega_{t}}, \\
\int_{1}^{\infty} f(\gamma)^{\frac{1}{\gamma}} e^{-\frac{1}{\gamma} z_{t}} d \gamma & =e^{\omega_{t}}
\end{aligned}
$$

where $z_{t} \equiv \ln Z_{t}$. The resource constraint (19) establishes a mapping between $z_{t}$ and $\omega_{t}$. The inverse of this mapping, $z\left(\omega_{t}\right)$, defines the logarithm of the shadow price, $z_{t}$, as a function of relative consumption $\omega_{t}$. Thus, consumption policy is a function of $\omega_{t}, c_{t}^{*}\left(Y_{t}, X_{t} ; \gamma\right)=c_{t}^{*}\left(\omega_{t} ; \gamma\right)$.

\section{Proof of Lemma 2}

Given the general expression for the stock price,

$$
\begin{gathered}
P_{t}=\mathrm{E}_{t} \int_{t}^{\infty} \exp \left(-\rho(s-t)-z_{t}+z_{s}+x_{t}-x_{s}\right) Y_{s} d s \\
\frac{P_{t}}{Y_{t}}=\exp \left(x_{t}-z_{t}-y_{t}\right) \mathrm{E}_{t} \int_{t}^{\infty} \exp \left(-\rho(s-t)+z_{s}+y_{s}-x_{s}\right) d s \\
=\exp \left(-z\left(\omega_{t}\right)-\omega_{t}\right) \mathrm{E}\left[\int_{t}^{\infty} \exp \left(-\rho(s-t)+z\left(\omega_{s}\right)+\omega_{s}\right) d s \mid \omega_{t}\right] .
\end{gathered}
$$

The price-dividend ratio is well defined. Since $f(\gamma)$ has compact support, the function $z(\omega)$ is asymptotically linear as $|\omega| \rightarrow \infty$ and therefore the expectation of $\exp \left(z\left(\omega_{t}\right)\right)$ is finite.

\section{Proof of Lemma 3}

In equilibrium, the instantaneous Sharpe ratio is equal to the absolute value of the volatility of the stochastic discount factor (e.g., Duffie (1996, Section 6.D)), $\left|\sigma_{z}\right|=-\sigma z^{\prime}\left(\omega_{t}\right)$. To show that the aggregate curvature parameter is negatively related to relative consumption it is sufficient to 
establish that $z^{\prime \prime}\left(\omega_{t}\right)>0$. Differentiating (9) twice with respect to $\omega$ yields

$$
\int_{1}^{\infty} f(\gamma)^{\frac{1}{\gamma}} e^{-\frac{1}{\gamma} z\left(\omega_{t}\right)-\omega_{t}}\left(\frac{z^{\prime \prime}\left(\omega_{t}\right)}{\gamma}-\left(\frac{z^{\prime}\left(\omega_{t}\right)}{\gamma}+1\right)^{2}\right) d \gamma=0
$$

If there are at least two types of agents in the economy,

$$
\int_{1}^{\infty} f(\gamma)^{\frac{1}{\gamma}} e^{-\frac{1}{\gamma} z\left(\omega_{t}\right)-\omega_{t}}\left(\frac{z^{\prime}\left(\omega_{t}\right)}{\gamma}+1\right)^{2} d \gamma>0
$$

and the previous equality implies $z^{\prime \prime}\left(\omega_{t}\right)>0$.

\section{Properties of the Model with Homogeneous Preferences}

We establish some general properties of the stock price and return volatility in homogeneous economies. Abel (1999) derives explicit expressions for conditional moments of returns in a discretetime economy under the assumption that the standard of living depends on a single lag of the aggregate consumption process. The conditional moments of returns in his model are constant. As we demonstrate below, this is not the case in a model with a slow-varying standard of living.

The next lemma shows that the price-dividend ratio in homogeneous economies is a monotone, convex function of relative consumption.

Lemma 5 In a homogeneous economy with catching up with the Joneses preferences, the pricedividend ratio is:

(a) Increasing in the state variable $\omega_{t}$ for $\gamma>1$. Formally,

$$
\frac{d\left(P_{t} / Y_{t}\right)}{d \omega_{t}} \begin{cases}>0, & \gamma>1 \\ =0, & \gamma=1\end{cases}
$$

(b) It is a convex function of $\omega_{t}$ for $\gamma>1$.

Proof. (a) With homogeneous agents, from the definition of $z\left(\omega_{t}\right)$ we immediately have $z\left(\omega_{t}\right)=-\gamma \omega_{t}$. To simplify the notation, define $\bar{P} \equiv P / Y$. Then, the price function in (13) becomes

$$
\begin{aligned}
\bar{P} & =e^{(\gamma-1) \omega} \mathrm{E}_{0}\left[\int_{0}^{\infty} e^{-\rho t+(1-\gamma) \omega_{t}} d t \mid \omega_{0}=\omega\right] \\
& =e^{(\gamma-1) \omega}\left[\int_{0}^{\infty} e^{-\rho t+(1-\gamma) \mathrm{E}_{0}\left(\omega_{t}\right)+\frac{(1-\gamma)^{2}}{2} \operatorname{Var}_{0}\left(\omega_{t}\right)} d t\right] \\
& =e^{(\gamma-1) \omega} \cdot \int_{0}^{\infty} \kappa_{t} e^{(1-\gamma) e^{-\lambda t} \omega} d t
\end{aligned}
$$

where

$$
\kappa_{t} \equiv \exp \left\{-\rho t+\left[(1-\gamma)\left(1-e^{-\lambda t}\right) \bar{\omega}+\frac{\sigma^{2}(1-\gamma)^{2}}{4 \lambda}\left(1-e^{-2 \lambda t}\right)\right]\right\}>0 .
$$

Differentiating with respect to $\omega$ and rearranging terms, we obtain

$$
\frac{d \bar{P}}{d \omega}=(\gamma-1)\left(\bar{P}-\bar{P}_{1}\right)
$$


where

$$
\bar{P}_{1} \equiv e^{(\gamma-1) \omega} \cdot \int_{0}^{\infty} \kappa_{t} e^{(1-\gamma) e^{-\lambda t} \omega} e^{-\lambda t} d t .
$$

It is obvious that $\bar{P}>\bar{P}_{1}$. Thus, we have established part (a).

(b) Differentiating (20) again with respect to $\omega$ gives

$$
\frac{d^{2} \bar{P}}{d \omega^{2}}=(\gamma-1)\left[\frac{d \bar{P}}{d \omega}\right]+(\gamma-1)\left[\frac{d \bar{P}}{d \omega}-(\gamma-1) \bar{P}\right]+(\gamma-1)^{2} \bar{P}_{2}
$$

where

$$
\bar{P}_{2} \equiv e^{(\gamma-1) \omega} \cdot \int_{0}^{\infty} \kappa_{t} e^{(1-\gamma) e^{-\lambda t} \omega} e^{-2 \lambda t} d t .
$$

Again, it is obvious that $\bar{P}>\bar{P}_{1}>\bar{P}_{2}$. Using (20) and rearranging terms,

$$
\begin{aligned}
\frac{d^{2} \bar{P}}{d \omega^{2}} & =2(\gamma-1)^{2}\left(\bar{P}-\bar{P}_{1}\right)-(\gamma-1)^{2}\left[\bar{P}-\bar{P}_{2}\right] \\
& =(\gamma-1)^{2}\left(\bar{P}+\bar{P}_{2}-2 \bar{P}_{1}\right) .
\end{aligned}
$$

Thus, to complete the proof, it remains to show that $\bar{P}+\bar{P}_{2}-2 \bar{P}_{1}>0$. But,

$$
\begin{aligned}
& \bar{P}+\bar{P}_{2}-2 \bar{P}_{1} \\
& =e^{(\gamma-1) \omega} \cdot \int_{0}^{\infty} \kappa_{t} e^{(1-\gamma) e^{-\lambda t} \omega}\left(1+e^{-2 \lambda t}-2 e^{-\lambda t}\right) d t \\
& =e^{(\gamma-1) \omega} \cdot \int_{0}^{\infty} \kappa_{t} e^{(1-\gamma) e^{-\lambda t} \omega}\left(1-e^{-\lambda t}\right)^{2} d t .
\end{aligned}
$$

Since all the terms involved are positive, we have $\bar{P}+\bar{P}_{2}-2 \bar{P}_{1}>0$. This completes the proof.

We can gain more intuition behind Lemma 5 by examining the marginal utility process. Formally, the marginal utility of the representative investor follows

$$
\frac{d U_{C}}{U_{C}}=\left(\lambda(\gamma-1) \omega_{t}-\gamma \mu+\frac{\sigma^{2} \gamma}{2}(\gamma+1)\right) d t-\gamma \sigma d B_{t}
$$

Thus, a change in the state variable affects future marginal utility except when $\gamma=1$. For $\gamma>1$, an increase in $\omega$ raises the intertemporal marginal rate of substitution (the ratio of future to current marginal utility). In other words, the stock becomes more expensive relative to the current dividend, as the state prices for future dividend claims increase. This explains the positive relation between the price-dividend ratio and the state variable.

Lemma 6 In the homogeneous economy with catching up with the Joneses preferences, (a) the Sharpe ratio is constant and given by $\gamma \sigma$.

(b) The instantaneous interest rate is given by

$$
r_{t}=\rho-\lambda(\gamma-1)\left(\omega_{t}-\bar{\omega}\right)+\lambda \bar{\omega}-\frac{1}{2} \gamma^{2} \sigma^{2}
$$


Lemma 6 follows from the standard consumption CAPM. The lemma shows that the price of risk $\pi_{t}$ is constant. The instantaneous interest rate inherits the stochastic behavior of the state variable. Moreover, its variation is increasing in both $\lambda$ and risk aversion.

As (21) indicates, the growth rate of the marginal utility is state-dependent for $\gamma \neq 1$. This implies that volatility also depends on the state of the economy. The next lemma formally shows that the conditional volatility of stock returns is also a monotone function of the state.

Lemma 7 In an economy with homogeneous preferences, the following properties hold:

(a) Return volatility is increasing in the state variable $\omega$ for all risk preferences other than the logarithmic type. Formally,

$$
\frac{d \sigma_{R}\left(\omega_{t}\right)}{d \omega_{t}} \begin{cases}>0, & \text { for } \gamma \neq 1 \\ =0, & \text { for } \gamma=1\end{cases}
$$

(b) The instantaneous correlation between changes in volatility and returns is positive for $\gamma \neq 1$ and equal to zero for $\gamma=1$.

Proof. (a) From the expression for return volatility,

$$
\begin{aligned}
\frac{d \sigma_{R}(\omega)}{d \omega} & =\sigma\left[\frac{d^{2} \bar{P} / d \omega^{2}}{\bar{P}}-\left(\frac{d \bar{P} / d \omega}{\bar{P}}\right)^{2}\right] \\
& =\sigma(\gamma-1)^{2}\left[\frac{\bar{P}_{2}}{\bar{P}}-\left(\frac{\bar{P}_{1}}{\bar{P}}\right)^{2}\right],
\end{aligned}
$$

where the second equality follows from part (b) of Lemma 5. Showing the expression in brackets is positive is equivalent to showing

$$
\left(\int_{0}^{\infty} \bar{\kappa}_{t} d t\right)\left(\int_{0}^{\infty} \bar{\kappa}_{t}\left(1-e^{-\lambda t}\right)^{2} d t\right)>\left(\int_{0}^{\infty} \bar{\kappa}_{t}\left(1-e^{-\lambda t}\right) d t\right)^{2}
$$

where $\bar{\kappa}_{t} \equiv \kappa_{t} e^{(1-\gamma) e^{-\lambda t} \omega}$. (22) follows from Schwartz's inequality.

(b) The instantaneous correlation between changes in volatility and returns is given by

$$
\operatorname{sgn}\left(\frac{d \sigma_{R}}{d \omega} \cdot \sigma_{R}\right)=\operatorname{sgn}\left(\frac{d \sigma_{R}}{d \omega} \cdot\left(\sigma+\sigma \frac{d(P / Y) / d \omega}{(P / Y)}\right)\right) .
$$

As we have shown in Lemma $5, \operatorname{sgn}\left(d \sigma_{R} / d \omega\right) \geq 0$. In addition, according to (20),

$$
\frac{d(P / Y) / d \omega}{(P / Y)}=(\gamma-1)\left(1-\frac{\bar{P}_{1}}{\bar{P}}\right) \geq-1
$$

therefore

$$
\operatorname{sgn}\left(\sigma\left(1+\frac{d(P / Y) / d \omega}{(P / Y)}\right)\right) \geq 0 .
$$

This establishes the result of part (b). 


\section{References}

Abel, Andrew B., 1990, "Asset Prices Under Habit Formation and Catching Up with the Joneses", American Economic Review, vol.80, pp.38-42.

Abel, Andrew B., 1999, "Risk Premium and Term Premia in General Equilibrium", Journal of Monetary Economics, vol.43, pp.3-33.

Bakshi, Gurdip S., and Zhiwu Chen, 1996, "The Spirit of Capitalism and Stock-Market Prices", American Economic Review, vol. 86, no.1, pp.133-157.

Basak, Suleyman, and Domenico Cuoco, 1998, "An Equilibrium Model with Restricted Stock Market Participation", Review of Financial Studies, vol.11, no.2, pp.309-41.

Benninga, Simon, and Joran Mayshar, 1997, "Heterogeneity and Option Pricing", working paper, Tel-Aviv University and Hebrew University.

Black, Fischer, 1976, "Studies of Stock, Price Volatility Changes", Proceedings of the 1976 Meetings of the Business and Economics Statistics Section, American Statistical Association, pp.177-181.

Brav, Alon, George M. Constantinides and Christopher C. Geczy, 1999, "Asset Pricing with Heterogeneous Consumers and Limited Participation: Empirical Evidence", working paper, University of Chicago.

Campbell, John Y., and John H. Cochrane, 1999, "By Force of Habit: A ConsumptionBased Explanation of Aggregate Stock Market Behavior", Journal of Political Economy, vol.107, no.2, pp.205-251.

Campbell, John Y., and Ludger Hentschel, 1992, "No News is Good News: An Asymmetric Model of Changing Volatility in Stock Returns", Journal of Financial Economic, vol.31, pp.281-318.

Campbell, John Y., Andrew W. Lo, A. Craig MacKinlay, 1997, The Econometrics of Financial Markets, Princeton University Press, Princeton, NJ.

Campbell, John Y., and Robert J. Shiller, 1988, "The Dividend-Price Ratio and Expectations of Future Dividends and Discount Factors", Review of Financial Studies, vol.1, pp.195-227.

Chan, Yeung L., and L. Kogan, 2000, "Catching Up with the Joneses: Heterogeneous Preferences and the Dynamics of Asset Prices", Working paper, Rodney L. White Center, Wharton School, University of Pennsylvania.

Constantinides, George M., 1982, "Intertemporal Asset Pricing with Heterogeneous Consumers and without Demand Aggregation", Journal of Business, vol.55, no.2, pp.253267. 
Constantinides, George M., 1990, "Habit Formation: A Resolution of the Equity Premium Puzzle", Journal of Political Economy, vol.98, no.3, pp.519-543.

Constantinides, George M., and Duffie Darrell, 1996, "Asset Pricing with Heterogeneous Consumers", Journal of Political Economy, vol.104, no.2, pp.219-240.

Cox, John, and Chi-fu Huang, 1989, "Optimal Consumption and Portfolio Policies when Asset Prices Follow a Diffusion Process", Journal of Economic Theory, vol.49, pp.3383.

Cox, John, Jonathan Ingersoll and Stephen Ross, 1985, "An Intertemporal General Equilibrium Model of Asset Prices", Econometrica, vol.53, pp.363-384.

Detemple, Jerome B., and Shashidhar Murthy, 1994, "Intertemporal Asset Pricing with Heterogeneous Beliefs", Journal of Economic Theory, vol. 62, pp.294-320.

Detemple, Jerome B., and Fernando Zapatero, 1991, "Asset Prices in an Exchange Economy with Habit Formation", Econometrica, vol.59, no.6, pp.1633-1657.

Duffie, Darrell, 1996. Dynamic Asset Pricing Theory, Princeton University Press, Princeton, New Jersey.

Duffie, Darrell, and Chi-fu Huang, 1985, "Implementing Arrow-Debreu Equilibrium by Continuous Trading of Few Long-Lived Securities", Econometrica, vol.53, pp.13371356.

Dumas, Bernard, 1989, "Two-Person Dynamic Equilibrium in the Capital Market", The Review of Financial Studies, vol.2, no.2, pp.157-188.

Dybvig, Philip H., and L.C.G. Rogers, 1997, "Recovery of Preferences from Observed Wealth in a Single Realization", Review of Financial Studies, vol. 10, pp.151-174.

Ferson, Wayne E., and Campbell R. Harvey, 1991, "The Variation of Economic Risk Premiums", Journal of Political Economy, vol. 99, pp. 385-415.

Ferson, Wayne E., and George M. Constantinides, 1991, "Habit Persistence and Durability in Aggregate Consumption: Empirical Tests", Journal of Financial Economics, vol.29, pp.199-240.

Gali, Jordi, 1994, "Keeping Up with the Joneses: Consumption Externalities, Portfolio Choice, and Asset Prices", Journal of Money, Credit and Banking, vol.26, pp.1-8.

Grossman, Sanford J., and Zhongquan Zhou, 1996, "Equilibrium Analysis of Portfolio Insurance", Journal of Finance, vol.LI, no.4, pp.1379-1403.

Harvey, Campbell R., 1991, "The Specification of Conditional Expectations", Working paper, Duke University.

Heaton, John C., 1995, "An Empirical Investigation of Asset Pricing with Temporally Dependent Preferences Specifications", Econometrica, vol.63, no.3, pp.681-717. 
Heaton, John C., and Deborah J. Lucas, 1996, "Evaluating the Effects of Incomplete Markets on Risk Sharing and Asset Pricing", Journal of Political Economy, vol.104, no.3, pp. $443-87$.

Heaton, John C., and Deborah J. Lucas, 1999, "Stock Prices and Fundamentals", NBER Macroeconomics Annual, (MIT Press, Cambridge, MA), pp. 213-242.

Hindy, Ayman, and Chi-fu Huang, 1992, "Intertemporal Preferences For Uncertain Consumption: A Continuous Time Approach", Econometrica, vol.60, no.4, pp.781-801.

Hindy, Ayman, and Chi-fu Huang, 1993, "Optimal Consumption and Portfolio Rules with Durability and Local Substitution", Econometrica, vol.61, no.1, pp.85-121.

Hindy, Ayman, Chi-fu Huang and Steven H. Zhu, 1997, "Optimal Consumption and Portfolio Rules with Durability and Habit Formation", Journal of Economic Dynamics and Control, vol.21, pp.525-550.

Karatzas, Ioannis, J. Lehoczky and Steven Shreve, 1990, "Existence and Uniqueness of Multi-Agent Equilibrium in a Stochastic, Dynamic Consumption/Investment Model", Mathematics of Operations Research, vol. 15, pp. 80-128.

Lucas, Robert E., Jr., 1978, "Asset Prices in an Exchange Economy", Econometrica, vol.46, pp.1429-1446.

Mankiw, N. Gregory, 1986, "The Equity Premium and the Concentration of Aggregate Shocks", Journal of Financial Economics, vol.17, pp.211-219.

Mehra, Rajinish, and Edward Prescott, 1985, "The Equity Premium: A Puzzle", Journal of Monetary Economics, vol.15, pp.145-161.

Merton, Robert C., 1990, Continuous-Time Finance, Blackwell Publishers, Cambridge, MA.

Nelson, Charles R., and Myung J. Kim, 1993, "Predictable Stock Returns: The Role of Small Sample Bias", Journal of Finance, vol. 48, pp. 641-661.

Rubinstein, Mark, 1974, "An Aggregation Theorem for Securities Markets", Journal of Financial Economics, vol.1, pp.225-244.

Ryder, Harl E., Jr., and Geoffrey M. Heal, 1973, "Optimal Growth with Intertemporally Dependent Preferences", Review of Economic Studies, vol.40, pp.1-33.

Schwert, G. William, 1989, "Why Does Stock Market Volatility Change Over Time?", Journal of Finance, vol.XLIV, no.5, pp.1115-1153.

Siegel, Jeremy J., 1992, "The Real Rate of Interest from 1800-1990", Journal of Monetary Economics, vol.29, pp.227-252. 
Storesletten, Kjetil, Chris I. Telmer, and Amir Yaron, 2001, "Asset Pricing with Idiosyncratic Risk and Overlapping Generations," Working paper, University of Pennsylvania.

Sundaresan, Suresh M., 1989, "Intertemporally Dependent Preferences and the Volatility of Consumption and Wealth", The Review of Financial Studies, vol.2, no.1, pp.73-89.

Wang, Jiang, 1996, "The Term Structure of Interest Rates in a Pure Exchange Economy with Heterogeneous Investors", Journal of Financial Economics, vol.41, pp.75-110.

Weil, Philippe, 1989, "The Equity Premium Puzzle and the Riskfree Rate Puzzle", Journal of Monetary Economics, vol.24, pp.401-421. 


\begin{tabular}{lccc}
\hline Parameter & Variable & \multicolumn{2}{c}{ Model } \\
\cline { 3 - 4 } & & Heterogeneous & Homogeneous \\
\hline Mean consumption growth (\%) & $\mu$ & 1.80 & 1.80 \\
Standard deviation of consumption growth $(\%)$ & $\sigma$ & 4.02 & 4.02 \\
Degree of history-dependence in $X_{t}(\%)$ & $\lambda$ & 5.87 & 4.00 \\
Subjective discount factor (\%) & $\rho$ & 5.21 & 5.30 \\
Risk aversion coefficient & $\gamma$ & - & 8.14 \\
Cross-section of utility weights & $a_{1}$ & 3.53 & - \\
& $a_{2}$ & .030 & - \\
\hline
\end{tabular}

Table 1: Parameters of the heterogeneous and the homogeneous model. 


\begin{tabular}{lccc}
\hline Statistic & Data & \multicolumn{2}{c}{ Model } \\
\cline { 3 - 4 } & & Heterogeneous & Homogeneous \\
\hline $\mathrm{E}[\Delta c]^{*}$ & 1.72 & 1.72 & 1.72 \\
$\sigma[\Delta c]^{*}$ & 3.28 & 3.28 & 3.28 \\
$\mathrm{E}\left[r_{B}\right]^{*}$ & 1.83 & 1.83 & 1.83 \\
$\sigma\left[r_{B}\right]^{*}$ & 3.0 & 2.90 & 4.02 \\
$\rho_{1}\left[r_{B}\right]$ & .85 & .96 & .97 \\
$\mathrm{E}\left[r_{S}-r_{B}\right]^{*}$ & 4.18 & 4.18 & 4.18 \\
$\sigma\left[r_{S}-r_{B}\right]^{*}$ & 17.74 & 17.79 & 17.70 \\
$\mathrm{E}\left[r_{S}-r_{B}\right] / \sigma\left[r_{S}-r_{B}\right]^{*}$ & .24 & .24 & .24 \\
$\exp (\mathrm{E}[p-y])$ & 22.48 & 28.76 & 27.21 \\
$\sigma[p-y]$ & .28 & .51 & .49 \\
$\bar{\omega}$ & - & .32 & .47 \\
$\sigma[\omega]$ & - & .12 & .14 \\
\hline
\end{tabular}

Table 2: Moments of simulated and historical data. The historical moments are based on the 1889-1994 sample period (Campbell, Lo and MacKinlay (1997, Table 8.1) report the first two moments of stock and bond returns). All returns are defined at annual frequency. Consumption is averaged over every year and the price-dividend ratio is defined at the end of the year. "** denotes the moments that model parameters were chosen to match. Whenever possible, moments of the model are computed by integrating with respect to the long-run stationary distribution of the model. In remaining cases moments are estimated based on 50,000 years of simulated data. All returns are annual percentages. $\Delta c$ is log consumption growth; $r_{B} \equiv \int_{0}^{1} r_{t} d t$ is $\log$ bond return; $r_{S} \equiv \int_{0}^{1} \mu_{R, t}-\frac{1}{2} \sigma_{R, t}^{2} d t$ is log stock return; $p-y$ is $\log$ price-dividend ratio. $\rho_{1}\left[r_{B}\right]$ denotes the first-order autocorrelation coefficient of the interest rate process. The "Data" column shows the estimate of this coefficient for nominal annual commercial paper returns between 1989 and 1994. Ex post real interest rate autocorrelation is 0.52 . This estimate is biased downward because of unanticipated inflation. 


\begin{tabular}{lrrrrr}
\hline & \multicolumn{5}{c}{ Lag $j$ (Years) } \\
\cline { 2 - 6 } Statistic & \multicolumn{1}{c}{2} & 3 & \multicolumn{1}{c}{5} & 7 \\
\hline$\left(r_{S}-r_{B}\right)_{t},\left(r_{S}-r_{B}\right)_{t+j}$ & .03 & -.21 & .13 & -.16 & .13 \\
Data & -.02 & -.02 & -.02 & -.02 & -.02 \\
Heterogeneous model & .01 & .01 & .00 & .00 & .01 \\
Homogeneous model & & & & & \\
$\sum_{i=1}^{j} \rho\left[\left(r_{S}-r_{B}\right)_{t},\left(r_{S}-r_{B}\right)_{t-i}\right]$ & .03 & -.18 & -.05 & -.28 & -.15 \\
$\quad$ Data & -.02 & -.04 & -.06 & -.08 & -.10 \\
Heterogeneous model & .01 & .01 & .02 & .02 & .03 \\
Homogeneous model & & & & & \\
$(p-y)_{t},\left(r_{S}-r_{B}\right)_{t+j}$ & -.18 & -.27 & -.08 & -.21 & -.05 \\
Data & -.07 & -.06 & -.06 & -.06 & -.06 \\
Heterogeneous model & .02 & .01 & .02 & .01 & .01 \\
Homogeneous model & & & & & \\
$(p-y)_{t},\left|r_{S}-r_{B}\right|_{t+j}$ & -.20 & -.06 & -.06 & -.18 & -.12 \\
Data & -.14 & -.13 & -.11 & -.11 & -.11 \\
Heterogeneous model & .15 & .13 & .13 & .13 & .13 \\
Homogeneous model & & & & & \\
\hline
\end{tabular}

Table 3: Autocorrelations and cross-correlations of simulated and historical data. All returns are annual. For each statistic, we report a historical estimate and the corresponding population moments of the heterogeneous and the homogeneous model, estimated based on 50,000 years of simulated data. 


\begin{tabular}{|c|c|c|c|c|c|c|}
\hline \multirow{3}{*}{$\begin{array}{c}\text { Horizon } \\
\text { (years) }\end{array}$} & \multirow{2}{*}{\multicolumn{2}{|c|}{ Data }} & \multicolumn{4}{|c|}{ Model } \\
\hline & & & \multicolumn{2}{|c|}{ Heterogeneous } & \multicolumn{2}{|c|}{ Homogeneous } \\
\hline & Coefficient & $R^{2}$ & Coefficient & $R^{2}$ & Coefficient & $R^{2}$ \\
\hline 1 & -.12 & .04 & -.03 & .01 & .01 & .00 \\
\hline 2 & -.30 & .10 & -.05 & .01 & .01 & .00 \\
\hline 3 & -.35 & .11 & -.07 & .01 & .02 & .00 \\
\hline 5 & -.64 & .23 & -.09 & .02 & .02 & .00 \\
\hline 7 & -.73 & .25 & -.11 & .02 & .03 & .00 \\
\hline
\end{tabular}

Table 4: Long horizon regressions. Log excess stock returns are regressed on the log pricedividend ratio. The table reports the slope coefficients of the regressions and the $R^{2}$ for historical data, the heterogeneous model and the homogeneous model. Historical estimates are based on the 1889-1994 sample. Statistics for the model are estimated based on 50,000 years of simulated data. 
Figure 1: Utility weights. Utility weights $f(\gamma)$ in the objective of the social planner are plotted as a function of individual risk aversion.

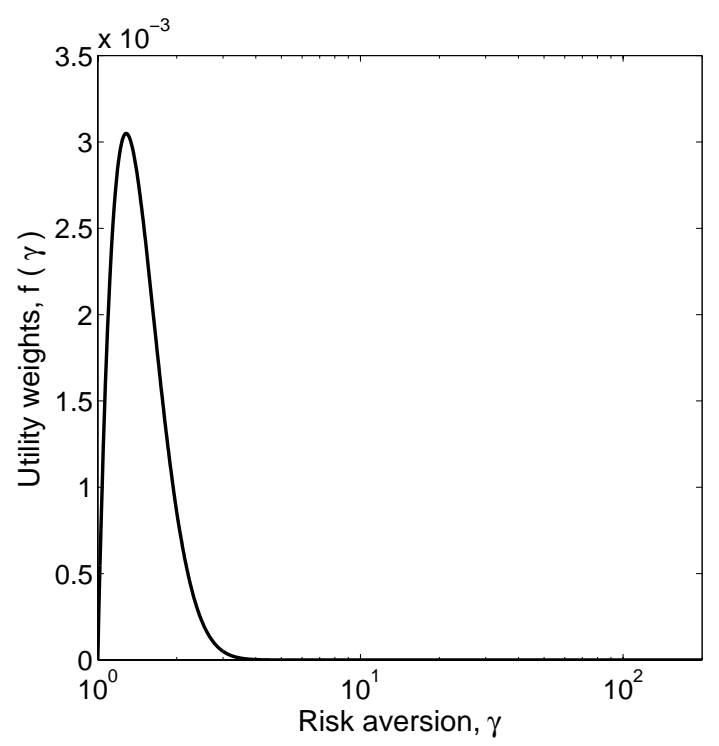


Figure 2: Price-dividend ratio. The logarithm of the price-dividend ratio, $p-y$, is plotted as a function of relative consumption. The solid line corresponds to the heterogeneous model, the broken line corresponds to the homogeneous model.

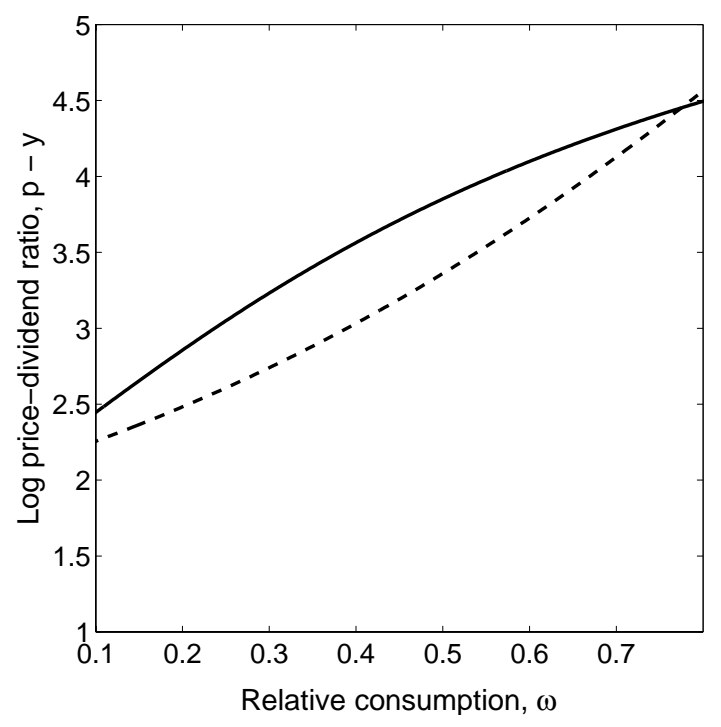


Figure 3: Conditional moments of stock returns. Instantaneous Sharpe ratio and conditional volatility of stock returns are plotted as functions of relative consumption. The solid line corresponds to the heterogeneous model, the broken line corresponds to the homogeneous model.

Panel A: Sharpe ratio

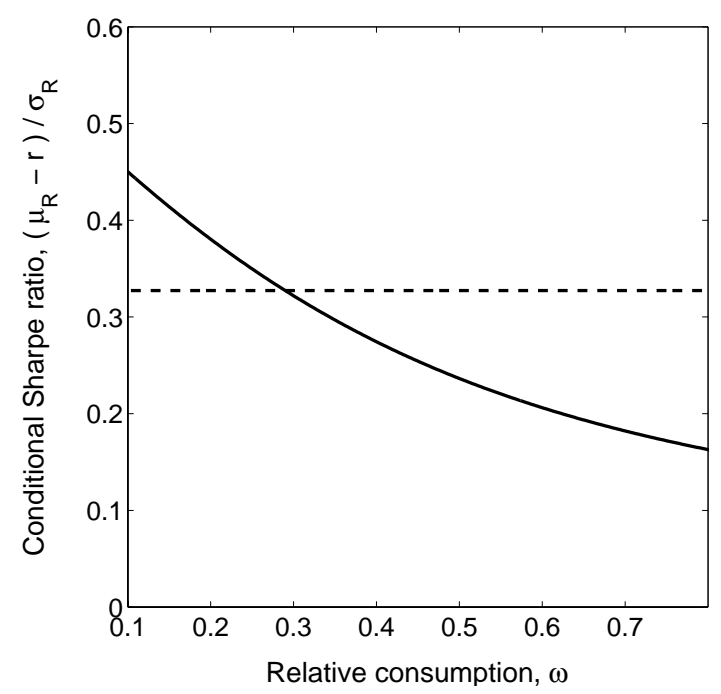

Panel B: Volatility

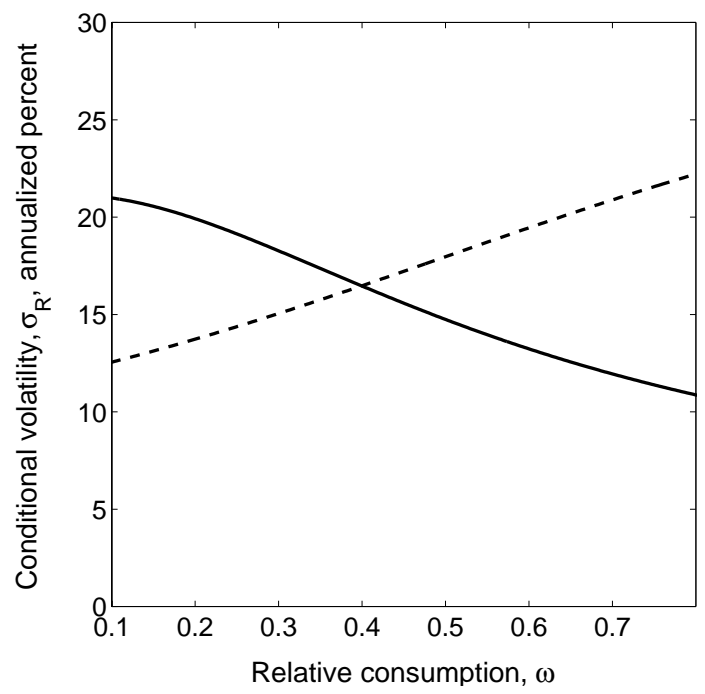


Figure 4: Cross-sectional distribution of wealth. For every value of $\gamma$ (horizontal axis), the line shows the fraction of the aggregate wealth controlled by individuals with risk aversion less than or equal to $\gamma$. The dotted, solid and broken lines correspond to three values of relative consumption, $\bar{\omega}-\sigma[\omega], \bar{\omega}$, and $\bar{\omega}+\sigma[\omega]$ respectively.

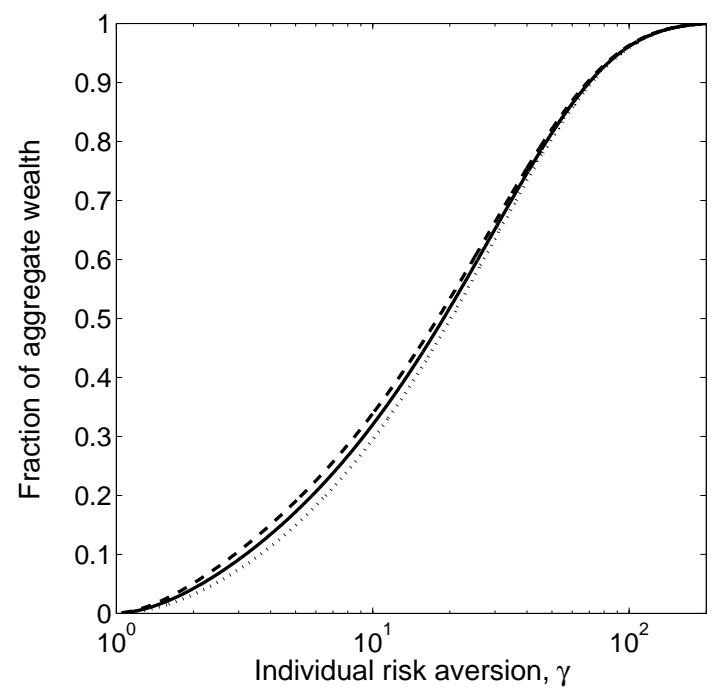


Figure 5: Conditional volatility of returns in homogeneous economies. The conditional volatility of stock returns is plotted as a function of relative consumption in three homogeneous economies. These economies differ only with respect to the risk aversion parameter $\gamma$, which takes values of 6,8 , and 10 . All other model parameters are fixed at their calibrated values: $\rho=5.30 \%$ and $\lambda=4.02 \%$.

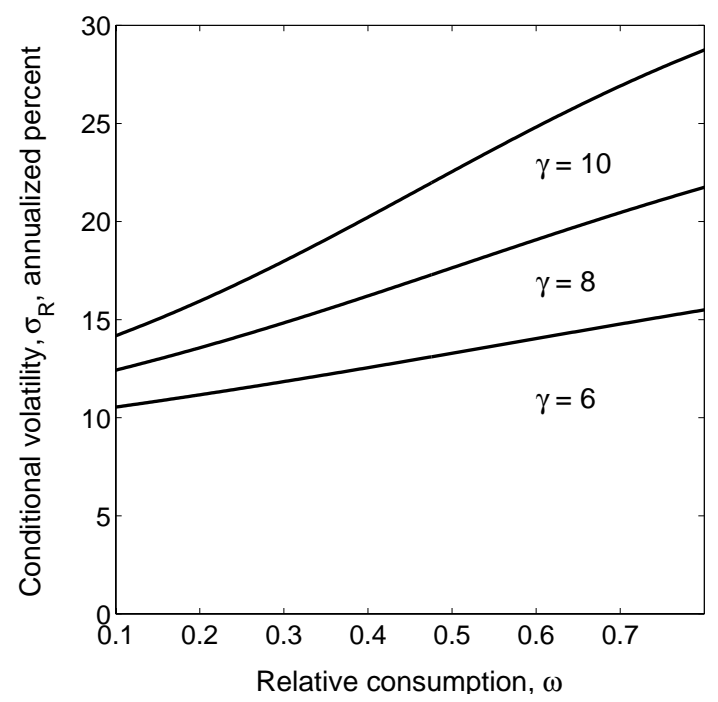


Figure 6: Risk-free rate and the risk premium. Risk-free rate $r$ and the conditional risk premium $\mu_{R}-r$ are plotted as functions of relative consumption. The solid line corresponds to the heterogeneous model, the broken line corresponds to the homogeneous model.

Panel A: Risk-free rate

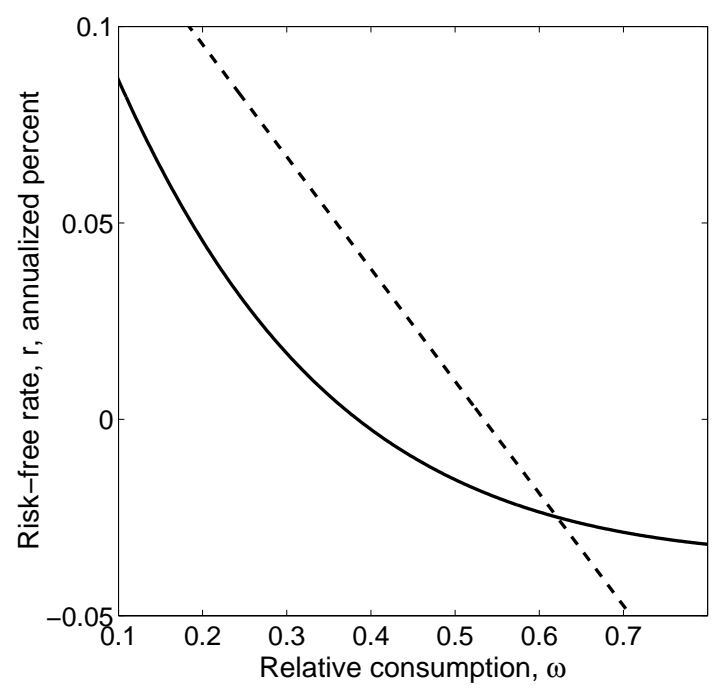

Panel B: Risk premium

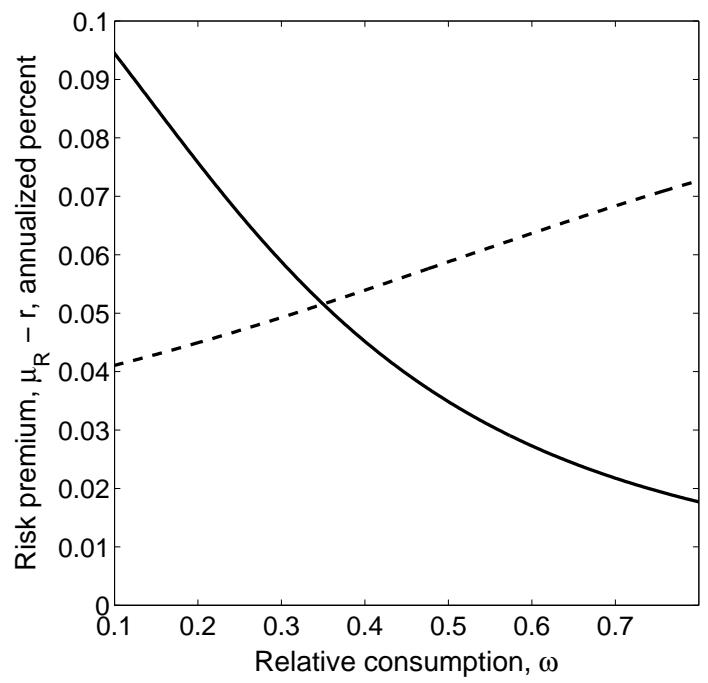


Figure 7: Individual risk exposure. Risk exposure is summarized by the instantaneous market beta of the individual wealth process, $\beta_{W, M}$. For every value of the individual market beta (horizontal axis), the graph shows the fraction of the aggregate wealth controlled by individuals with risk exposure less than or equal to $\beta_{W, M}$. The dotted, solid and broken lines correspond to three values of the aggregate state (relative consumption), $\bar{\omega}-\sigma[\omega], \bar{\omega}$, and $\bar{\omega}+\sigma[\omega]$ respectively.

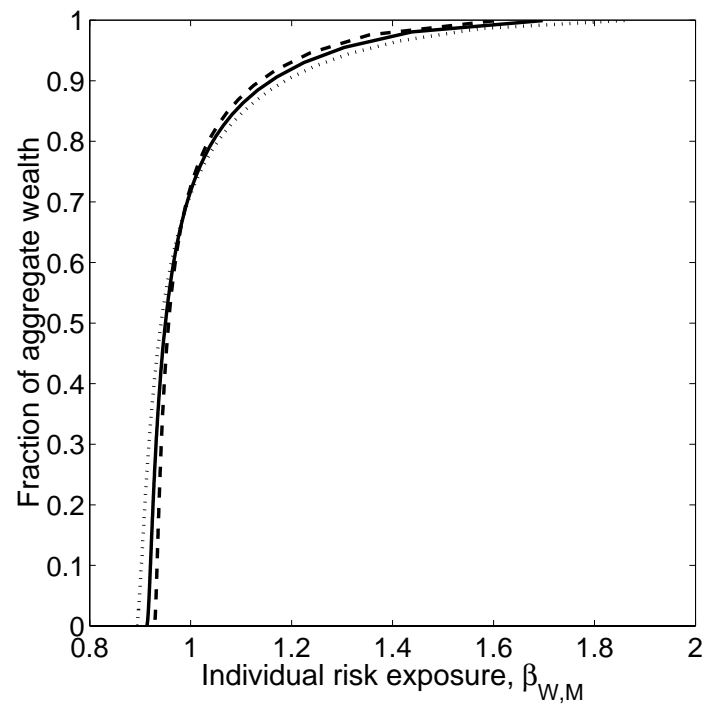


Figure 8: Individual consumption volatility. For every value of the instantaneous volatility of the individual consumption process (horizontal axis, measured as a fraction of the volatility of the aggregate endowment $\sigma$ ), the graph shows the fraction of the aggregate wealth controlled by individuals with consumption volatility less than or equal to that value. The dotted, solid and broken lines correspond to three values of the aggregate state (relative consumption), $\bar{\omega}-\sigma[\omega], \bar{\omega}$, and $\bar{\omega}+\sigma[\omega]$ respectively.

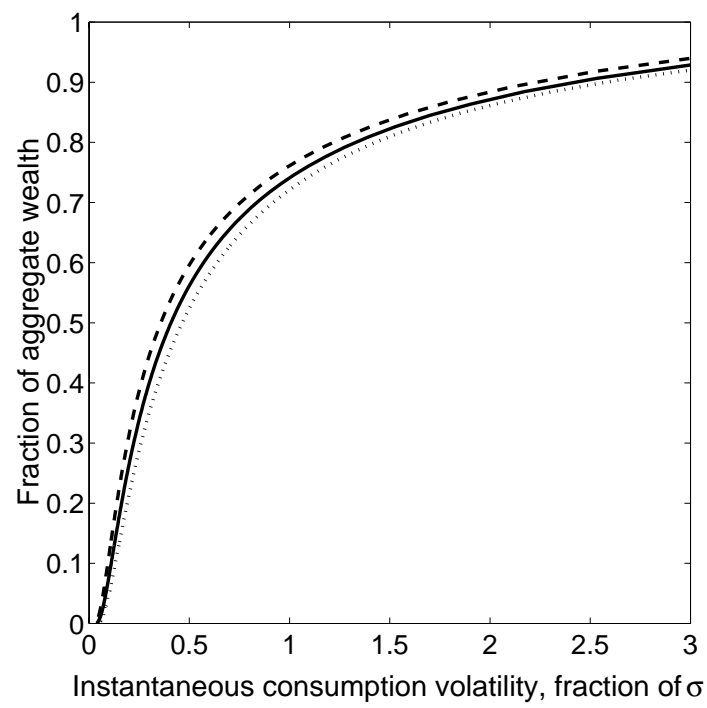

